\title{
Psychometric Properties of the General Anxiety Disorders-7 Scale Using Categorical Data Methods: A Study in a Sample of University Attending Ethiopian Young Adults
}

This article was published in the following Dove Press journal:

Neuropsychiatric Disease and Treatment

\section{Md Dilshad Manzar (iD) \\ Ahmad H Alghadir ${ }^{2}$ \\ Shahnawaz Anwer (iD) 2,3 \\ Mazen Alqahtani ${ }^{4}$ \\ Mohammed Salahuddin ${ }^{5,6}$ \\ Habtamu Acho Addo (iD ${ }^{5}$ \\ Wakuma Wakene Jifar ${ }^{7}$ \\ Nofaa Ali Alasmee ${ }^{8}$ \\ 'Department of Nursing, College of Applied Medical Sciences, Majmaah University, Majmaah, I 1952, Saudi Arabia; \\ ${ }^{2}$ Rehabilitation Research Chair, College of Applied Medical Sciences, King Saud University, Riyadh, Saudi Arabia; \\ ${ }^{3}$ Department of Building and Real Estate, Hong Kong Polytechnic University, \\ Kowloon, Hong Kong Special \\ Administrative Region; ${ }^{4}$ Department of Physiotherapy, College of Applied Medical Sciences, Majmaah University, Majmaah I 1952, Saudi Arabia; ${ }^{5}$ Department of Pharmacy, College of Medicine and Health Sciences, Mizan-Tepi University (Mizan Campus), Mizan-Aman, Ethiopia; ${ }^{6}$ Pharmacology Division, Department of BioMolecular Sciences, University of Mississippi, Oxford, MS, USA; ${ }^{7}$ Department of Pharmacy, College of Health Science, Mettu University, Metu, Ethiopia; ${ }^{8}$ Faculty of Nursing, King Abdulaziz University, Jeddah, Saudi Arabia}

Correspondence: Shahnawaz Anwer Email shahnawaz.anwer@connect.polyu. hk
Background: Few studies have investigated the psychometric validation of the General Anxiety Disorders-7 Scale (GAD-7) using appropriate data assumptions. This study examined the reliability, factorial validity, divergent validity, and item analysis of the GAD-7 using categorical data methods in a sample of Ethiopian young adults.

Methods: A sample of 270 students in the age group (18-20 years) was recruited during February-May of 2017 in this cross-sectional study using simple random sampling. The participants completed a tool for socio-demographic details, the GAD-7, and the Perceived Stress Scale-10 (PSS-10).

Results: The cumulative variance rule ( $>40 \%$ ), the scree test, Kaiser's criteria (Eigenvalues $>1$ ), and the parallel analysis found a 1-factor model for the GAD-7 (factor loadings, 0.38 to $0.63)$. Fit indices suggested a 1-factor model: the tests applied included the weighted root mean square residual (0.030), comparative fit index (1.000), the goodness of fit index (1.00), root mean square error of approximation (0.037) and the non-normed fit index (1.00). McDonald's Omega (0.772) implied that the scores had adequate internal consistency. Divergent validity was supported by significant but weak correlations that were found between the GAD-7 and PSS-10 scores ( $\mathrm{r}=0.11$ to $0.25, p<0.05$ ).

Conclusion: The psychometric validity of the GAD-7 in Ethiopian university attending young adults was supported by the categorical data method.

Keywords: anxiety, Africa, stress, McDonald's omega, factor analysis

\section{Introduction}

Anxiety disorders are one of the most common and debilitating mental disorders across the world, affecting as much as $33.7 \%$ of the population in their lifetime. ${ }^{1}$ Generalized anxiety disorders (GAD) are among the most common types of anxiety disorders. This condition has a bimodal age of onset with an early-onset group, those who are 24 years and younger, and a late-onset group, those who are above 24 years of age. ${ }^{2}$ The onset of anxiety disorders in this age group is associated with poor academic outcomes, suicide risk, drug abuse, alcohol abuse, and risky sexual behavior. $^{3}$

Proper management of GAD requires an accurate assessment and diagnosis. However, GAD often remains underdiagnosed. ${ }^{4}$ This could be attributed to the lack of a gold-standard method for GAD diagnosis, and non-availability of expert 
psychiatrists, clinical psychologists in health facilities, especially in low- and middle-income countries. ${ }^{5}$ Therefore, alternative approaches, such as the use of screening tools and questionnaires, are required for identifying patients with GAD. One such screening instrument is the generalized anxiety disorders -7 scale (GAD-7), ${ }^{6}$ which has been validated in different populations previously. ${ }^{7,8}$ The GAD-7 is a brief and easy-to-use instrument designed to assess the symptoms of GAD as described in the Diagnostic and Statistical Manual of Mental Disorders-IV (DSM-IV). To give a reliable and valid measure of the intended conditions, screening tools must demonstrate acceptable psychometric characteristics in a given population. Moreover, this quality check is necessary before a tool is recommended for use in clinical practice and research.

Previous psychometric studies of anxiety tests, including the GAD-7, have focused on the investigation of their test-retest reliability, concurrent validity, and internal consistency. ${ }^{6,8}$ However, inconsistencies in factorial validity assessments and findings are seen across studies with reports showing four types of 1-Factor models (difference coming from correlated error terms), a 2-Factor as well as a bifactor model. ${ }^{9}$ Factorial validation is considered necessary to explore the validity of the theoretical construct underlying the test and to determine the best means for interpreting the item scores, as well as for addressing the issues of singularity, multicollinearity, and redundancy of the items. Additionally, considering the ordinal nature of the GAD-7 item scores, it may be technically better to use statistical methods suitable for such data. To the best of our knowledge, there is no psychometric validation study of GAD-7 with specific reference to African young adults, a group that is vulnerable to the development of anxiety and its potential complications. A systematic review of 48 reviews found that the prevalence of anxiety disorders, including GAD ranges between 4 to $25 \%$ in the general population, while the rates are $4.4 \%$ and 2.5 to $9.1 \%$ among Africans and young adults, respectively. ${ }^{10}$ Adolescents and young adults seem prone to mental disorders including anxiety, with studies reporting a lifetime prevalence of up to $30 \% .{ }^{11}$ A recent study among Ethiopian university students using the GAD-7 as the screening tool for anxiety disorders reported a prevalence of $21.9 \% .{ }^{12}$ Additionally, many predictors of anxiety and related mental diseases have been found to be common in Ethiopians such as epilepsy, people living with HIV, childhood sexual abuse, substance use, sleep disorders, low economic status, or food insecurity. ${ }^{13}$

In such a context, the availability of a GAD measure, which has been comprehensively validated in this age group, may be beneficial for an easy, efficient, and costeffective screening of the condition in this population. Therefore, the present study aimed to evaluate (a) the reliability, (b) factorial validity, (c) discriminative validity, and (d) preliminary item analysis based on the classical theory of GAD-7, using categorical data assumptions, in a sample of Ethiopian young adults.

\section{Methods}

\section{Participants}

For this study, a sample of 400 students were initially earmarked, of which 39 declined to participate, 76 were excluded (self-reported memory problems/use of neuropsychiatric medicine $(\mathrm{n}=16)$; age not in the 18-20 years range $(\mathrm{n}=60)$, and 15 did not report on the day of data collection). Finally, a study sample of 270 students in the young adult age group (18-20 years, BMI $=20.58 \pm$ $3.18 \mathrm{~kg} / \mathrm{m} 2$ ) participated during February-May of 2017 period for the present study (Figure 1). Students with active enrollment in the courses of the Mizan Campus of the Mizan-Tepi University at the time of the study with an age range of 18-20 years (a stage just after and overlapping with late adolescence) were included in this study. Participants with self-reported use of medications for neuropsychiatric conditions or self-report of memory problems were excluded to minimize chances of memory bias on the study outcome. There were neither construct-level nor item-level missing data for the GAD-7 scores in the study sample.

\section{Procedure}

This cross-sectional study was approved by the Institutional review board of the College of Medicine and Health Sciences, Mizan-Tepi University, Ethiopia. All participants signed a written informed consent form. Furthermore, the study was carried out following the Helsinki guidelines for the ethical conduct of scientific studies involving human subjects. Participants meeting the eligibility criteria were identified and recruited for participation in the study. Data were collected using a participants' characteristics questionnaire, Perceived Stress Scale-10 (PSS-10), and the GAD-7 scale. All questionnaires used in the study were administered in the 


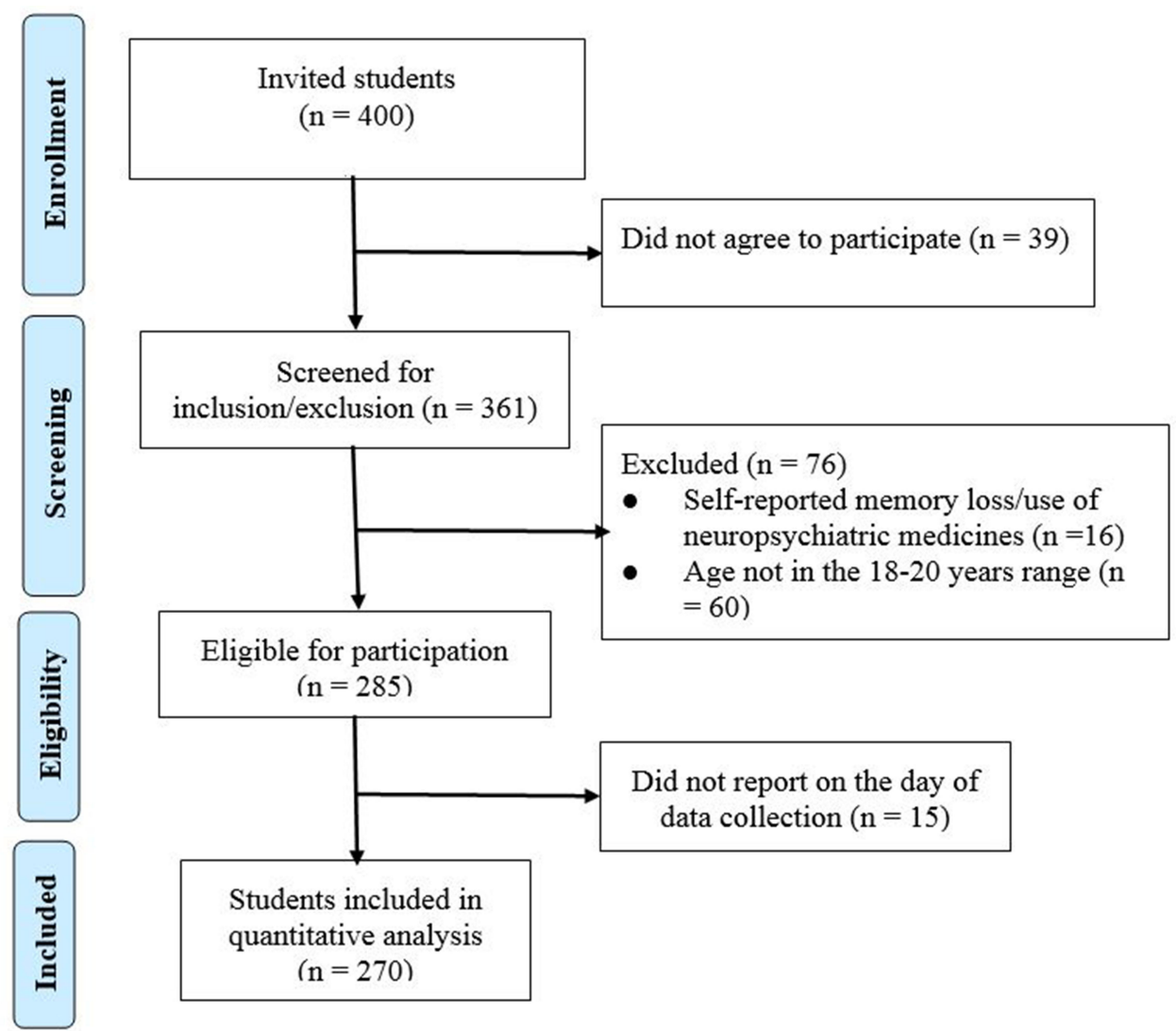

Figure I Flowchart with the detail of the sampling selection procedure.

English language, in as much as the medium of instruction in all Ethiopian government universities is English.

\section{Measures}

\section{Perceived Stress Scale-10}

The Perceived Stress Scale-10 (PSS-10) was designed to quantify the self-reported level of stress by evaluating participants' thoughts and feelings in the one month prior to the test's administration. Each item in the 10-item questionnaire is scored on a 5-point Likert scale, where 0 ' indicates 'never' and ' 5 ' indicates 'very often'. The total of possible PSS scores ranges from 0 to 40 . The final PSS score is calculated by reversing responses (e.g., $0=4,1=3,2=2,3=1 \& 4=0$ ) to the four positively stated items (items $4,5,7$,

\& 8) and then summing across all scale items. ${ }^{14}$ High scores indicate higher levels of stress. Six of the items on the PSS-10 scale relate to perceived or felt levels of stress, while the remaining four items concern the strategies used by the test taker to cope with stress. The PSS tool has been determined to have adequate psychometric properties in different population groups. ${ }^{13}$ Moreover,
PSS-10 has been reported to show favorable psychometric measures such as convergent validity, structural validity, reliability, and item discrimination among university students in Ethiopia. ${ }^{13}$ Previous studies reported an adequate internal consistency of PSS-10 as measured by Cronbach's alpha ( 0.74 to 0.91$)^{15}$ and McDonald's Omega (0.68 to $0.80) .{ }^{13}$ A recent study on university students in Saudi Arabia found an adequate internal consistency of the PSS-10 as measured by Cronbach's alpha of 0.78 and 0.71 for the PSS Factor-1 and Factor-2 scores, respectively. ${ }^{16}$

\section{Generalized Anxiety Disorder - 7 Scale}

The GAD-7 scale is a 7-item questionnaire used to quantify the self-reported magnitude of anxiety symptoms in the participants during the previous fortnight. The GAD-7 uses a framework of anxiety symptoms described in the DSM-IV. ${ }^{6}$ Each item is scored on a Likert scale from 0 (not at all) to 4 (nearly every day). The scores of all items are added to give the final score ranging from 0 to 21 . The GAD-7 has acceptable psychometric validity in some populations, ie, testretest reliability, diagnostic validity, convergent validity, 
factorial validity, and internal consistency. ${ }^{9}$ Additionally, a recent study on university students in Saudi Arabia found an adequate internal consistency of GAD-7 as measured by Cronbach's alpha (0.80). ${ }^{17}$

\section{Participants' Characteristics Questionnaire}

Participants completed a questionnaire to record their demographics and general health status. Information such as their age, gender, attendance in the classes, ethnicity, presence of chronic health conditions, and years of university education.

\section{Statistical Analysis}

Data analysis was carried out using the Statistical Package for Social Sciences (SPSS) version 23.0 and Factor 10.8.04. Participants' characteristics, reliability, item analysis, and divergent validity were explored using descriptive statistics, Spearman correlation coefficient test, Mardia's test of skewness and kurtosis, McDonald's Omega, and the greatest lower bound for reliability.

The Kaiser-Meyer-Olkin (KMO) Test of Sampling Adequacy (95\% confidence interval), Bartlett's Test of Sphericity, determinant, communality, and inter-item Spearman correlations were employed to determine the sample size adequacy/suitability of the GAD-7 scores for factor analysis. Ceiling and floor effects were also assessed using the criterion that the highest or lowest scores were reported by at least $15 \%$ of the respondents, respectively. ${ }^{18}$

Tetrachoric correlations (estimated using bootstrap sampling) for inter-item scores of the GAD-7 were used for semiconfirmatory factor analysis. Exploratory factor analysis (EFA) was employed using robust diagonally weighted least squares (RDWLS) with a Promin rotation. Measures used for factor retention were Kaiser's criteria (Eigenvalue $\geq 1$ ), the scree test, the cumulative variance explained rule $(>40 \%)$, and the robust parallel analysis. A range of fit indices, including the Comparative Fit Index (CFI), the goodness of fit index (GFI), weighted root mean square residual (WRMR), root mean square error of approximation (RMSEA), non-normed fit index (NNFI), $\chi^{2}$, and $\chi^{2} / \mathrm{df}$, were also employed following standard recommendations. ${ }^{19}$ Among these fit statistic indices, RMSEA with values of 0.05 or less indicated that the data exhibited a good fit. ${ }^{19}$ The findings of a WRMR $(\leq 0.05)$ and $\chi^{2} / \mathrm{df}(\leq 3)$ implied that the data showed an adequate and exceptional fit. ${ }^{19}$ A value $(\geq 0.95)$ for CFI, NNFI, and GFI indicated an excellent fit. ${ }^{19}$
The effectiveness and quality of the explored factor structure of GAD-7 were quantified using the factor determinacy index (FDI) and marginal reliability. A value greater than 0.9 of FDI is optimal for establishing reliability in individual assessment. ${ }^{20}$ Marginal reliability, calculated as a square of the FDI, is used as a measure of the reliability of the corresponding factor score. ${ }^{21}$ Explained common variance (ECV) of 0.7 to 0.8 helps in further fitting a unidimensional model based on the common variance of a set of measured items. Ferrando et al suggested the use of the mean of item residual absolute loading (MIREAL) for a second factor to reflect a departure from unidimensionality if values exceeded $0.3 .^{20}$

\section{Results}

\section{Participant's Characteristics and Preliminary Item Analysis}

The socio-demographic characteristics of the participants are shown in Table 1. All participants were young adults studying in a university (18-20 years). Approximately threefourths of the participants were in the normal body mass index (BMI) range (Table 1). About $78 \%$ of the students had an attendance rate of more than $90 \%$. About $90 \%$ did not have any chronic health diseases. About half of the study sample reported having mild anxiety symptoms. Overall, the anxiety scores for the students (assessed using GAD-7) were in a moderate range. Univariate descriptive statistics, item discrimination, and homogeneity results are reported in Table 2. The tests of univariate skewness and kurtosis showed that item 1 was skewed (the absolute value of $Z$ score of skewness was more than 3.29) and two-item scores had kurtosis problems as implied by the absolute value of $Z$ score of kurtosis above 3.29 (Table 2). However, the GAD7 total score was neither skewed, nor did it show evidence of kurtosis as determined by the Z-score of skewness and kurtosis, which was below $|3.29|$.

Although there was no evidence of either a floor or ceiling effect for the GAD-7 total score, floor and ceiling effects were nevertheless found in the GAD-7 item scores. Only one item (item-7) of the GAD-7 showed a ceiling effect, whereas all seven of the items showed a floor effect ${ }^{18}$ (Table 2).

\section{Factorial Validity}

\section{Sample Adequacy/Suitability for Factor Analysis}

The factorisation of the data was further supported by the results of inter-item correlations between GAD-7 items, 
Table I Participant Characteristics

\begin{tabular}{|c|c|}
\hline Characteristics & Mean \pm SD/Frequency \\
\hline Age (years) & $\mid 9.61 \pm 0.62$ \\
\hline 18 & $19(7.0)$ \\
\hline 19 & $68(25.2)$ \\
\hline 20 & $183(67.8)$ \\
\hline \multicolumn{2}{|l|}{ Body mass index $\left(\mathrm{Kg} / \mathrm{m}^{2}\right)$} \\
\hline Underweight & $66(22.2)$ \\
\hline Normal & $188(69.6)$ \\
\hline Over-weight & $16(5.9)$ \\
\hline Obese & $6(2.2)$ \\
\hline \multicolumn{2}{|l|}{ Gender } \\
\hline Male & $193(71.5)$ \\
\hline Female & $77(28.5)$ \\
\hline \multicolumn{2}{|l|}{ Attendance (percentage) } \\
\hline Up to 80 & $27(10.0)$ \\
\hline $80-90$ & $32(11.9)$ \\
\hline $90-100$ & $211(78.1)$ \\
\hline \multicolumn{2}{|l|}{ Ethnicity } \\
\hline Amhara & $85(31.5)$ \\
\hline Bench & $17(6.3)$ \\
\hline Keffa & $5(1.9)$ \\
\hline Oromo & $81(30.0)$ \\
\hline Tigre & $3(1.1)$ \\
\hline Wolaita & $8(3.0)$ \\
\hline Unreported & $7 \mid(26.3)$ \\
\hline \multicolumn{2}{|l|}{ Chronic health conditions } \\
\hline Yes & $28(10.4)$ \\
\hline No & $242(89.6)$ \\
\hline \multicolumn{2}{|l|}{ Years of university education } \\
\hline I year & $143(53.0)$ \\
\hline 2 year & $92(34.1)$ \\
\hline 3 year & $8(3.0)$ \\
\hline 4 year & II (4.I) \\
\hline 5 year & $16(5.9)$ \\
\hline PSS & $20.2 \pm 6.0$ \\
\hline GAD total score & $7.1 \pm 4.1$ \\
\hline \multicolumn{2}{|l|}{ Anxiety* } \\
\hline Normal (0-4) & $63(23.3)$ \\
\hline Mild anxiety (5-9) & $114(42.2)$ \\
\hline Moderate anxiety $(10-14)$ & $79(29.3)$ \\
\hline Severe anxiety $(15-2 \mid)$ & $14(5.2)$ \\
\hline
\end{tabular}

Note: *Based on GAD-7 total score.

Abbreviations: SD, standard deviation; PSS, Perceived Stress Scale- 10 total score; $\mathrm{GAD}$, generalized anxiety disorder.

where about one-third ( 8 out of 21 ) of the inter-item correlations were more than 0.3 (Table 3 ). Additionally, as shown in Table 2, communality conditions were satisfactory for all
GAD-7 items (above 0.2), ${ }^{22}$ except for item 4. The data collected using GAD-7 was appropriate for factor analysis, as indicated by the results of the following sample size adequacy/suitability indices: Bartlett's test of sphericity ( $p$ $<0.001)$, the determinant score (0.368), and the KaiserMeyer-Olkin test of sampling adequacy $(0.82)^{23}$ (Table 4$)$.

\section{Exploratory Factor Analysis}

The EFA results are reported in Table 5. As shown, four measures were used to extract the number of factors (s) in the EFA (ie, the cumulative variance rule ( $>40 \%$ ), the scree test, Kaiser's criteria (Eigenvalues $>1$ ), and parallel analysis). All of these measures unanimously found a 1-factor model for the GAD-7. The factor loadings of the GAD-7 items are presented in Table 2. As shown, all seven items of GAD-7 were loaded on a single factor, with the factor loadings ranging from 0.38 to 0.63 . Comrey and Lee (2013) suggested a minimum factor loading score of $0.32 .^{25}$

\section{Fit Indices}

All fit statistic indices provided adequate model fit to the data, ie, the 1-factor model followed the specified guidelines for CFI (1.000), GFI (1.000), WRMR (0.030), RMSEA (0.000 (0.00-0.037)) and NNFI (1.000). Moreover, $\chi^{2} / \mathrm{df}$ was in the ideal range, ie, $0.615 .^{20}$ Robust mean and variance-adjusted $\chi^{2}$ was nonsignificant $\left(\chi^{2}(5)=8.605, \mathrm{p}=0.859\right)$, further indicating the absolute fit of the model.

\section{Effectiveness and Quality of Factor Score Estimates and Measures of Closeness to Unidimensionality}

As displayed in Table 4, the values used to determine the quality and effectiveness of the one-factor structure of the GAD-7 in young adults were the factor determinacy index (FDI) (0.885) and marginal reliability (0.783). Measures of closeness to unidimensionality; ECV was 0.906, while MIREAL value was 0.214 .

\section{Internal Consistency and Item Discrimination}

As shown in Table 4, both measures used for the internal consistency assessment demonstrated adequate internal consistency, the greatest lower bound for reliability (0.813), ${ }^{24}$ and the McDonald's Omega (0.772). ${ }^{25}$ The analysis of item-total correlations revealed that the scores of all GAD-7 items were correlated significantly with the GAD-7 total score $(r=0.47$ to $0.65, \mathrm{p}<0.01)$ (Table 2 ). 
Table 2 Univariate Descriptive Statistics, Communality and Factor Loadings of the Generalized Anxiety Disorder (GAD)-7 Scale Among Young Adults

\begin{tabular}{|c|c|c|c|c|c|c|c|c|c|c|c|}
\hline \multirow{3}{*}{$\begin{array}{l}\text { Items of } \\
\text { the } \\
\text { GAD-7 }\end{array}$} & \multicolumn{2}{|c|}{ Skewness } & \multicolumn{2}{|c|}{ Kurtosis } & \multirow{3}{*}{$\begin{array}{l}\text { Item-Total } \\
\text { Correlations }\end{array}$} & \multirow{3}{*}{$\begin{array}{c}\text { Communality } \\
\qquad\left(h^{2}\right)^{*}\end{array}$} & \multirow{3}{*}{$\begin{array}{c}\text { Factor } \\
\text { Loading }^{*}\end{array}$} & \multirow{2}{*}{\multicolumn{4}{|c|}{$\begin{array}{l}\text { Percentage } \\
\text { Distribution Across } \\
\text { Item Scores }\end{array}$}} \\
\hline & \multirow{2}{*}{$\begin{array}{l}\text { Statistics } \\
\text { (SE) }\end{array}$} & \multirow[t]{2}{*}{ Z Score } & \multirow{2}{*}{$\begin{array}{l}\text { Statistics } \\
\text { (SE) }\end{array}$} & \multirow[t]{2}{*}{ Z Score } & & & & & & & \\
\hline & & & & & & & & 0 & I & 2 & 3 \\
\hline Item - I & $0.60(0.15)$ & 4.01 & $-.46(0.30)$ & -1.54 & $0.579 *$ & 0.324 & 0.569 & 34.4 & 39.6 & 19.3 & 6.7 \\
\hline Item - 2 & $0.44(0.15)$ & 2.94 & $-.91(0.30)$ & -3.08 & $0.627^{*}$ & 0.386 & 0.621 & 36.7 & 30.7 & 25.6 & 7.0 \\
\hline Item - 3 & $0.45(0.15)$ & 3.05 & $-.94(0.30)$ & -3.18 & $0.655^{*}$ & 0.399 & 0.632 & 32.6 & 33.3 & 20.7 & 13.3 \\
\hline Item - 4 & $0.31(0.15)$ & 2.08 & $-.73(0.30)$ & -2.48 & $0.478^{*}$ & 0.145 & 0.381 & 26.7 & 39.3 & 27.0 & 7.0 \\
\hline Item - 5 & $0.34(0.15)$ & 2.32 & $-.99(0.30)$ & -3.34 & $0.650^{*}$ & 0.361 & 0.601 & 33.0 & 30.7 & 27.0 & 9.3 \\
\hline Item - 6 & $0.39(0.15)$ & 2.61 & $-.89(0.30)$ & -3.00 & $0.601 *$ & 0.336 & 0.579 & 31.9 & 33.7 & 25.2 & 9.3 \\
\hline Item - 7 & $0.26(0.15)$ & 1.76 & $-1.16(0.30)$ & -3.91 & $0.635^{*}$ & 0.375 & 0.612 & 28.1 & 31.1 & 23.3 & 17.4 \\
\hline
\end{tabular}

Notes: ${ }^{*} \mathrm{p}<0.01$; ${ }^{\#}$ Spearman correlation coefficient; ${ }^{*}$ diagonally weighted least squares for unrotated solution.

Abbreviation: SE, standard error.

Table 3 Inter-Item Correlation Matrix of the Generalized Anxiety Disorder (GAD)-7 Scale Among Young Adults

\begin{tabular}{|l|l|l|l|l|l|l|l|}
\hline Items of the GAD-7 & Item-I & Item-2 & Item-3 & Item-4 & Item-5 & Item-6 & Item-7 \\
\hline Item-I & & & & & & \\
\hline Item-2 & $0.239^{* *}$ & & & & & \\
\hline Item-3 & $0.317^{* *}$ & $0.342^{* *}$ & & & & \\
\hline Item-4 & $0.209^{* *}$ & $0.218^{* *}$ & $0.155^{*}$ & & & \\
\hline Item-5 & $0.265^{* *}$ & $0.314^{* *}$ & $0.373^{* *}$ & $0.230^{* *}$ & & & \\
\hline Item-6 & $0.282^{* *}$ & $0.283^{* *}$ & $0.263^{* *}$ & $0.187^{* *}$ & $0.325^{* *}$ & & \\
\hline Item-7 & $0.278^{* *}$ & $0.349 * *$ & $0.304^{* *}$ & $0.18 I^{* *}$ & $0.269 * *$ & $0.312^{* *}$ & \\
\hline
\end{tabular}

Notes: $* p<0.05 ; * * p<0.01$.

\section{Divergent Validity}

As displayed in Table 6, the scores for all GAD-7 items were correlated significantly with the PSS score $(\mathrm{p}<0.05$ for items 1, 3, and 6; $\mathrm{p}<0.01$ for all other items). However, the correlation was weak $(r=0.11$ to 0.24$)$. A similar weak and significant correlation was found between GAD total score and PSS-10 total score ( $p<$ $0.01, r=0.25$ ).

\section{Discussion}

This is the first study to assess the psychometric characteristics of the GAD-7 in a sample of African young adults. Secondly, the study employed a novel strategy of categorical data assumptions to investigate the factorial validity, discriminative validity, and internal consistency of GAD-7.
A newly established and innovative methodology to investigate the effectiveness and quality of factor score estimates and measures of closeness to unidimensionality was also employed. Overall, the results of this study showed that the unidimensional structure of the GAD-7 had sufficient internal consistency, strong internal homogeneity, divergent validity, and item discrimination in young adults.

\section{Preliminary Item Analysis}

The issue of univariate distribution for items of the GAD-7 scores, ie, the presence of skewness and kurtosis, supported the application of categorical data methods for factor analysis and internal consistency assessment. ${ }^{26}$ Similar to our findings of a floor effect, García-Campayo et al reported a floor effect for two items of GAD-7 in the Spanish population. ${ }^{27}$ 
Table 4 Multivariate Descriptive, Sample Size Adequacy, Quality and Effectiveness of Factor Score, and Reliability Measures of the Generalized Anxiety Disorder (GAD)-7 Scale Among Young Adults

\begin{tabular}{|l|c|}
\hline Measures & Values \\
\hline $\begin{array}{l}\text { Multivariate descriptive } \\
\text { Mardia's skewness }\end{array}$ & $X^{2}(\mathrm{df}=84)=143.02 \mathrm{I}$, \\
& $\mathrm{P}=0.999$ \\
Mardia's kurtosis & $X^{2}=-0.833, \mathrm{p}=0.202$ \\
\hline $\begin{array}{l}\text { Effectiveness and quality of factor score } \\
\text { estimates* }\end{array}$ & \\
Factor Determinacy Index (FDI) & 0.885 \\
Expected a posteriori & 0.783 \\
marginalreliability & \\
\hline Sample size adequacy & \\
Bartlett's test of Sphericity & $X^{2}(\mathrm{df}=2 \mathrm{I})=266.8$, \\
Determinant & $\mathrm{P}<0.00 \mathrm{I}$ \\
KMO (95\% confidence interval) & 0.368 \\
\hline Internal consistency & $0.8 \mathrm{I} 9(0.802-0.853)$ \\
Greatest Lower Bound to Reliability & \\
McDonald's Omega & 0.813 \\
\hline
\end{tabular}

Notes: Kaiser-Meyer-Olkin Test of Sampling Adequacy (KMO); *for the I-factor structure of the GAD-7 scale.

However, Sousa et al did not find major evidence of a floor effect, but their study sample showed the presence of a ceiling effect in Portuguese psychiatry patients. ${ }^{8}$ In this study, the sample comprised of a nonclinical population of university students who were not undergoing treatment for psychiatric conditions. A similar trend for a floor effect has been reported for questionnaire instruments measuring other clinical features in nonclinical populations. ${ }^{28}$

\section{Sample Adequacy/Suitability for Factor Analysis}

This is the first study to rigorously assess the adequacy/ suitability of the dataset for factor analysis. Most of the previous studies that have investigated the factorial validity of the GAD-7 either did not assess sample adequacy/suitability or else they used only one measure to conclude the factorability of the GAD-7 scores in their respective study populations. ${ }^{22,27,29-31}$ The underreporting of sample adequacy/suitability by previous studies investigating the factorial validity of the GAD7 is contrary to recommended norms. ${ }^{19}$ In our study, the results of KMO, the value of the determinant, Bartlett's test of sphericity, and moderate to strong inter-item correlations all support the conclusion that GAD-7 scores were suitable for factor analysis. Although one of the items showed a low value for communality, the items were retained for factor analysis. The decision to retain item 4, irrespective of its low communality score (0.145) was taken because the item total correlation (0.478) and the factor loading score (0.38) for this item was in the inadequate range. ${ }^{32,33}$ Moreover, the deletion of the item would have meant the loss of relevant information. Furthermore, an inspection of Cronbach's alpha after deleting an item also did not favor the removal of the item. ${ }^{32}$

\section{Exploratory Factor Analysis}

The four methods of factor extraction, including the robust measure of parallel analysis, unanimously favored a one-factor structure for the GAD-7 in the study population of young adults. Few studies have employed multiple measures of factor extraction that have included a robust measure. ${ }^{34}$ Given this deficiency in the literature, it is recommended that multiple measures of factor extraction be employed, including at least one robust measure such as parallel analysis, the broken-stick method, etc. ${ }^{19}$ Factor loadings indicated an excellent level of correlation between the GAD-7 items and the factor score estimate ${ }^{33}$ since all of them were found to have more than the minimum recommended value of $0.32 .^{33}$

\section{Model Fit}

An excellent fit was implied by the model fit indices which were from different categories; this provided unanimous support for the unidimensionality of the GAD-7 in the study population of young adults. The unidimensional model for GAD-7 has been reported in Americans visiting primary health care, Americans of Hispanic descent who speak English or Spanish, and pregnant women in Peru. ${ }^{6,35}$ Moreover, the unidimensional model, as shown in this study of young adults, is not similar to modified models with correlated error terms, as has been reported in some populations. However, it is advisable to note that few of these studies employed measure(s) that would have indicated the suitability of their data for factor analysis. ${ }^{29,31}$ Therefore, the original 1-factor model of the GAD-7 was found to be adequately valid in young adults. ${ }^{6}$ 


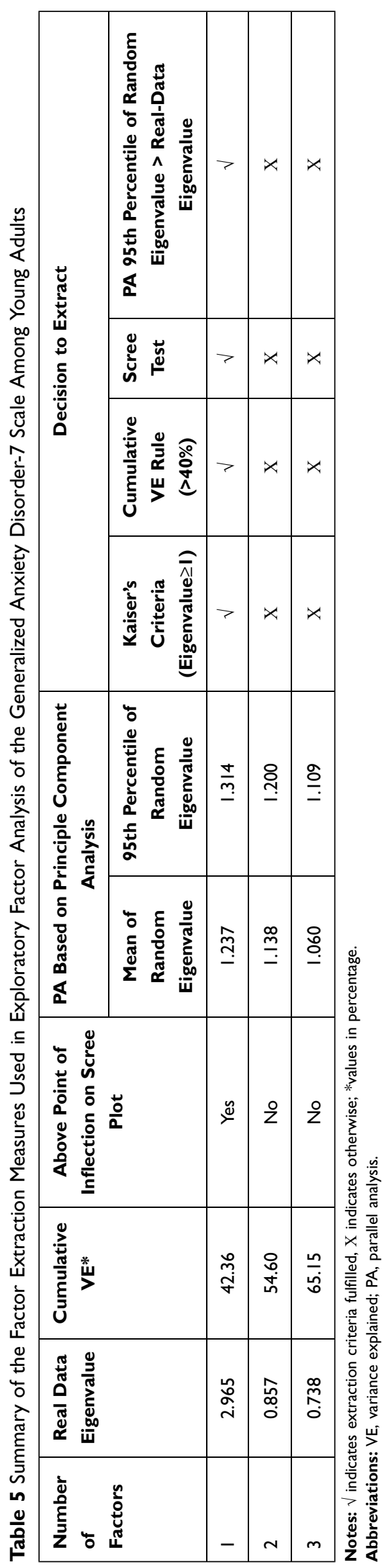

Effectiveness and Quality of Factor Score Estimates and Measures of Closeness to Unidimensionality

The factor determinacy was adequate for showing the applicability of the unidimensional model for research applications in young adults, according to the cut-off criteria (0.80) of Gorsuch. ${ }^{20}$ Furthermore, the values were very close to the limit needed for individual assessment (0.90). Marginal reliability is an index of precision as well as of sensitivity; higher values imply that respondents can be effectively differentiated based on their scores. The values for marginal reliability were adequate but slightly less than that required for individual assessment, ie, $0.8 .^{20}$ ECV further complemented the unidimensional nature of all seven items of the GAD-7 scale in this study population of older adolescents. ${ }^{36}$ Furthermore, support for the unidimensional loading of all item scores of the GAD-7 was indicated by the MIREAL value, which was less than 0.3 This adequately negated any divergence from unidimensionality by indicating an insignificant cross-load on the second factor. This is a relevant issue since some previous studies have suggested that a 2-Factor model was appropriate, while another suggested a bifactor model would be applicable. ${ }^{9,22}$

\section{Internal Consistency and Item Discrimination}

The internal consistency of the GAD-7 was adequate to good as indicated by the McDonald's omega and the greatest lower bound for reliability. The present study used McDonald's omega and the greatest lower bound of reliability as a better alternative to Cronbach's alpha, considering the high level of internal consistency of the ordinal level responses of the GAD-7. ${ }^{24}$ The internal consistency results indicate that the GAD-7 items were measuring a single underlying construct wherein a one-factor structure best characterized the data. ${ }^{37}$ The item-total correlations were greater than 0.3 ; the lowest value was 0.38 (between GAD-7 item-4 and the total score). This result supports the inference that the items of the GAD-7 are in line with the outcome. The finding further supports the conclusion that the items of the GAD-7 were measuring a similar construct and, thus demonstrating that the scale possessed adequate item discrimination. ${ }^{32}$ A direct comparison with previous studies is not possible since none of them used McDonald's omega or the greatest lower bound 
Table 6 Divergent Validity: Correlation Between the Perceived Stress Scale-10 and the Generalized Anxiety Disorder-7 Scale Scores Among Young Adults

\begin{tabular}{|l|c|}
\hline GAD Scores & PSS Score \\
\hline Item-I & $0.244^{* *}$ \\
Item-2 & $0.143^{*}$ \\
Item-3 & $0.18 I^{* *}$ \\
Item-4 & $0.140^{*}$ \\
Item-5 & $0.130^{*}$ \\
Item-6 & $0.173^{* *}$ \\
Item-7 & 0.115 \\
Total score & $0.255^{* *}$ \\
\hline
\end{tabular}

Notes: ${ }^{*} p<0.01 ; * p<0.05$.

of reliability to investigate the psychometric properties of the GAD-7.

\section{Divergent Validity}

The results demonstrated a positive and significant correlation between GAD-7 and PSS-10 scores. Ample evidence has shown that stress and anxiety are comorbid. ${ }^{38}$ Stress is one of the predisposing factors leading to anxiety. ${ }^{38}$ Even though stress and anxiety have a close relationship, it is important to bear in mind that both conditions are nonoverlapping and represent discrete psychological conditions. ${ }^{38}$ Therefore, the modest value of the correlation coefficient between GAD-7 scores with the measure of psychological distress does support divergent validity in the study population.

Some of the limitations that might better be taken into consideration while inferring generalizations from the current study are mentioned here. The study sample comprised of university students who were young adults; therefore, the lack of older adult groups may limit the generalizability of the study findings. Furthermore, modest sample size, nonassessment of other psychometric characteristics such as test-re-test reliability, concurrent validity, and measurement invariance of factorial validity are some of the methodological limitations that future studies should address. Future studies using categorical data assumptions should investigate the temporal and longitudinal measurement invariance of the GAD-7 factor structures in African populations. Multi-centric studies using samples from different regions in Africa may help in better understanding about the structural invariance of GAD-7 across African demographics. It may be interesting to investigate the item response theorybased robust item-level psychometric features of the GAD-7 in African populations. Nevertheless, the study provides valuable evidence about the adequate psychometric validity of the GAD-7 in young adults, an age group that is at an increased risk of GAD.

\section{Conclusions}

In summary, the unidimensional structure of the original English version of the GAD-7 showed an excellent fit, which was further complemented by additional measures. The instrument also showed adequate internal consistency, divergent validity, and item discrimination in the present sample of Ethiopian young adults. Therefore, the GAD-7 may be regarded as a valuable tool for primary health care physicians and counselors when screening young adults for GAD. The findings of this validity study imply that GAD-7 tool could help in easy and cost-effective screening of anxiety and GAD symptoms among young adults in the resource-limited health facilities of low- and middleincome countries of Africa.

\section{Acknowledgments}

We are grateful to the participants of the study. The authors are grateful to the Deanship of Scientific Research, King Saud University for funding through Vice Deanship of Scientific Research Chairs. The authors extend their appreciation to the Deanship of Scientific Research at Majmaah University for funding this work under Project Number No (RGP-2019-40).

\section{Author Contributions}

All authors made substantial contributions to the conception and design, acquisition of data, or analysis and interpretation of data; took part in drafting the article or revising it critically for important intellectual content; agreed to submit to the current journal; gave final approval of the version to be published; and agreed to be accountable for all aspects of the work.

\section{Funding}

This research was funded by Deanship of Scientific Research, King Saud University and Majmaah University. The funder had no role in the design of the study; in the collection, analyses, or interpretation of the data; in the writing of the manuscript, or in the decision to publish the results.

\section{Disclosure}

The authors declare no conflicts of interest. 


\section{References}

1. Bandelow B, Michaelis S. Epidemiology of anxiety disorders in the 21st century. Dialogues Clin Neurosci. 2015;17(3):327-335.

2. Rhebergen D, Aderka IM, van der Steenstraten IM, et al. Admixture analysis of age of onset in generalized anxiety disorder. $J$ Anxiety Disord. 2017;50:47-51. doi:10.1016/j.janxdis.2017.05.003

3. Donovan CL, Spence SH. Prevention of childhood anxiety disorders. Clin Psychol Rev. 2000;20(4):509-531. doi:10.1016/S0272-7358(99) 00040-9

4. Parmentier H, Garcia-Campayo J, Prieto R. Comprehensive review of generalized anxiety disorder in primary care in Europe. Curr Med Res Opin. 2013;29(4):355-367. doi:10.1185/03007995.2013.770731

5. Kasper S. Anxiety disorders: under-diagnosed and insufficiently treated. Int J Psychiatry Clin Pract. 2006;10(sup1):3-9. doi:10. 1080/13651500600552297

6. Spitzer RL, Kroenke K, Williams JB, Löwe B. A brief measure for assessing generalized anxiety disorder: the GAD-7. Arch Intern Med. 2006;166(10):1092-1097. doi:10.1001/archinte.166.10.1092

7. Seo JG, Park SP. Validation of the Generalized Anxiety Disorder-7 (GAD-7) and GAD-2 in patients with migraine. $J$ Headache Pain. 2015;16:97. doi:10.1186/s10194-015-0583-8

8. Sousa TV, Viveiros V, Chai MV, et al. Reliability and validity of the Portuguese version of the Generalized Anxiety Disorder (GAD-7) scale. Health Qual Life Outcomes. 2015;13:50. doi:10.1186/s12955015-0244-2

9. Doi S, Ito M, Takebayashi Y, Muramatsu K, Horikoshi M. Factorial validity and invariance of the 7-item Generalized Anxiety Disorder Scale (GAD-7) among populations with and without self-reported psychiatric diagnostic status. Front Psychol. 2018;9:1741. doi:10.3389/fpsyg.2018.01741

10. Remes O, Brayne C, Van Der Linde R, Lafortune L. A systematic review of reviews on the prevalence of anxiety disorders in adult populations. Brain Behav. 2016;6(7):e00497. doi:10.1002/brb3.497

11. Asselmann E, Beesdo-Baum K. Predictors of the course of anxiety disorders in adolescents and young adults. Curr Psychiatry Rep. 2015;17(2):7. doi:10.1007/s11920-014-0543-z

12. Manzar MD, Salahuddin M, Pandi-Perumal SR, Bahammam AS. Insomnia may mediate the relationship between stress and anxiety: a cross-sectional study in university students. Nat Sci Sleep. 2021;13:31. doi:10.2147/NSS.S278988

13. Manzar MD, Salahuddin M, Peter S, et al. Psychometric properties of the perceived stress scale in Ethiopian university students. $B M C$ Public Health. 2019;19(1):41. doi:10.1186/s12889-018-6310-z

14. Cohen S, Kamarck T, Mermelstein R. A global measure of perceived stress. J Health Soc Behav. 1983;24(4):385-396. doi:10.2307/2136 404

15. Lee E-H. Review of the psychometric evidence of the perceived stress scale. Asian Nurs Res. 2012;6(4):121-127. doi:10.1016/j. anr.2012.08.004

16. Anwer S, Manzar MD, Alghadir AH, Salahuddin M, Hameed UA. Psychometric analysis of the perceived stress scale among healthy university students. Neuropsychiatr Dis Treat. 2020;16:2389. doi:10. 2147/NDT.S268582

17. Alghadir A, Manzar MD, Anwer S, Albougami A, Salahuddin M. Psychometric properties of the generalized anxiety disorder scale among saudi university male students. Neuropsychiatr Dis Treat. 2020;16:1427-1432. doi:10.2147/NDT.S246526

18. Manzar MD, Salahuddin M, Alamri M, et al. Psychometric properties of the Epworth sleepiness scale in Ethiopian university students. Health Qual Life Outcomes. 2019;17(1):30. doi:10.1186/s12955019-1098-9

19. Manzar MD, BaHammam AS, Hameed UA, et al. Dimensionality of the Pittsburgh Sleep Quality Index: a systematic review. Health Qual Life Outcomes. 2018;16(1):89. doi:10.1186/s12955-018-0915-x
20. Ferrando PJ, Lorenzo-Seva U. Assessing the quality and appropriateness of factor solutions and factor score estimates in exploratory item factor analysis. Educ Psychol Meas. 2018;78(5):762-780. doi:10.11 77/0013164417719308

21. Brown A, Croudace T. Scoring and estimating score precision using multidimensional IRT. In: Reise SP, Revicki DA, editors. Handbook of Item Response Theory Modeling: Applications to Typical Performance Assessment (a Volume in the Multivariate Applications Series). New York: Routledge/Taylor \& Francis Group; 2015:30 $7-333$.

22. Bártolo A, Monteiro S, Pereira A. Factor structure and construct validity of the Generalized Anxiety Disorder 7-item (GAD-7) among Portuguese college students. Cad Saude Publica. 2017;33: e00212716. doi:10.1590/0102-311x00212716

23. Field A. Discovering Statistics Using IBM SPSS Statistics. sage; 2013.

24. Trizano-Hermosilla I, Alvarado JM. Best alternatives to cronbach's alpha reliability in realistic conditions: congeneric and asymmetrical measurements. Front Psychol. 2016;7:769. doi:10.3389/fpsyg.2016. 00769

25. Woodhouse B, Jackson PH. Lower bounds for the reliability of the total score on a test composed of non-homogeneous items: II: a search procedure to locate the greatest lower bound. Psychometrika. 1977;42(4):579-591. doi:10.1007/BF02295980

26. Crutzen R, Peters GY. Scale quality: alpha is an inadequate estimate and factor-analytic evidence is needed first of all. Health Psychol Rev. 2017;11(3):242-247. doi:10.1080/17437199.2015.1124240

27. García-Campayo J, Zamorano E, Ruiz MA, et al. Cultural adaptation into Spanish of the generalized anxiety disorder-7 (GAD-7) scale as a screening tool. Health Qual Life Outcomes. 2010;8(1):8. doi:10.1186/1477-7525-8-8

28. Manzar MD, Albougami A, Salahuddin M, Sony P, Spence DW, Pandi-Perumal SR. The Mizan meta-memory and meta-concentration scale for students (MMSS): a test of its psychometric validity in a sample of university students. BMC Psychol. 2018;6(1):59. doi:10.1186/s40359-018-0275-7

29. Kertz S, Bigda-Peyton J, Bjorgvinsson T. Validity of the Generalized Anxiety Disorder-7 Scale in an acute psychiatric sample. Clin Psychol Psychother. 2013;20(5):456-464.

30. Mills SD, Fox RS, Malcarne VL, Roesch SC, Champagne BR, Sadler GR. The psychometric properties of the Generalized Anxiety Disorder-7 Scale in Hispanic Americans with English or Spanish language preference. Cultur Divers Ethnic Minor Psychol. 2014;20 (3):463. doi:10.1037/a0036523

31. Terrill AL, Hartoonian N, Beier M, Salem R, Alschuler K. The 7-item generalized anxiety disorder scale as a tool for measuring generalized anxiety in multiple sclerosis. Int J MS Care. 2015;17 (2):49-56. doi:10.7224/1537-2073.2014-008

32. Wang M, Batt K, Kessler C, et al. Internal consistency and item-total correlation of patient-reported outcome instruments and hemophilia joint health score v2. 1 in US adult people with hemophilia: results from the pain, functional impairment, and quality of life (P-FiQ) study. Patient Prefer Adherence. 2017;11:1831. doi:10.2147/PPA.S141391

33. Comrey AL, Lee HB. A First Course in Factor Analysis. Psychology Press; 2013.

34. Sawaya H, Atoui M, Hamadeh A, Zeinoun P, Nahas Z. Adaptation and initial validation of the Patient Health Questionnaire-9 (PHQ-9) and the Generalized Anxiety Disorder-7 Questionnaire (GAD-7) in an Arabic speaking Lebanese psychiatric outpatient sample. Psychiatry Res. 2016;239:245-252. doi:10.1016/j.psychres.2016.03.030

35. Zhong Q-Y, Gelaye B, Zaslavsky AM, et al. Diagnostic validity of the generalized anxiety disorder-7 (GAD-7) among pregnant women. PLoS One. 2015;10(4):e0125096. doi:10.1371/journal. pone. 0125096

36. Rodriguez A, Reise SP, Haviland MG. Evaluating bifactor models: calculating and interpreting statistical indices. Psychol Methods. 2016;21(2):137-150. doi:10.1037/met0000045 
37. The SAGE encyclopedia of educational research, measurement, and evaluation. Thousand Oaks Thousand Oaks, California: SAGE Publications, Inc; 2018. Available from: http://sk.sagepub.com/refer ence/sage-encyclopedia-of-educational-research-measurementevaluation. Accessed February 26, 2021.
38. Nanthakumar S, Bucks RS, Skinner TC, et al. Assessment of the Depression, Anxiety, and Stress Scale (DASS-21) in untreated obstructive sleep apnea (OSA). Psychol Assess. 2017;29 (10):1201-1209. doi:10.1037/pas0000401

\section{Publish your work in this journal}

Neuropsychiatric Disease and Treatment is an international, peerreviewed journal of clinical therapeutics and pharmacology focusing on concise rapid reporting of clinical or pre-clinical studies on a range of neuropsychiatric and neurological disorders. This journal is indexed on PubMed Central, the 'PsycINFO' database and CAS, and is the official journal of The International Neuropsychiatric Association (INA). The manuscript management system is completely online and includes a very quick and fair peer-review system, which is all easy to use. Visit http://www.dovepress.com/testimonials.php to read real quotes from published authors.

Submit your manuscript here: https://www.dovepress.com/neuropsychiatric-disease-and-treatment-journal 